\title{
Factors Affecting Peak Expiratory Flow Rates in Children of 9-12 Years of Age
}

\author{
Shiyas KP', Gopi Mohan² \\ ${ }^{1}$ Dr. Shiyas KP, Associate Professor, Department of Pediatrics, Al-Azhar Medical College, Thodupuzha, Kerala, \\ India, ${ }^{2}$ Dr. Gopi Mohan, Associate Professor, Department of Pediatrics, Travancore Medical Collage, Kollam, \\ Kerala, India.
}

Address for Correspondence: Dr. Shiyas KP, Associate Professor, Department of Pediatrics, Al-Azhar Medical College, Thodupuzha, Kerala, India. E- mail: mediresearchdirect@gmail.com

\begin{abstract}
Introduction: Documentation of peak expiratory flow rate (PEFR) variability may be used to support the diagnosis of asthma and other respiratory disorders. Methodology: This study was carried to measure PEFR of 510 children age group 9 to 12 years of both sexes using a Mini Wright ${ }^{\mathrm{TM}}$ Peak Flow Meter. Results were analyzed to find out the normal values of peak expiratory flow rate at each age and either sex. The results were also analyzed to find out what factors influence the peak expiratory flow rate. Effect of age, sex, height, weight, chest circumference, socioeconomic status, passive smoking, cooking fuel, history of contact with tuberculosis and bronchial asthma in family were analyzed separately. Results: The average peak expiratory flow rate in boys was $272 \pm 53.16 \mathrm{~L} / \mathrm{min}$ and for girls was $252 \pm 45.09 \mathrm{~L} / \mathrm{min}$. For the given age boys have higher peak expiratory flow rate than girls. The peak expiratory flow rate shows very good correlation with height and weight in both sexes. A History of contact with tuberculosis is associated with lower peak expiratory flow rate. Children coming from homes with firewood being used as a fuel and passive smoking had lower peak expiratory flow-rate. No significant relation has been found between peak expiratory flow rate and socioeconomic status and family history of bronchial asthma. Conclusions: The peak expiratory flow rate values of children in study region were comparatively low to those of North Indian and Western children but more compared to urban south Indian children.
\end{abstract}

Keywords: Peak expiratory flow rate, pulmonary function, asthma, respiratory disease.

\section{Introduction}

Respiratory diseases represent the most common cause of death in children worldwide. The number of patients attending the outpatient department of hospital account for only a tip of the iceberg. The technical difficulties inherent in pulmonary function testing of young children are obstacles to the development of simple, clinically relevant procedures for assessment. Even in a time when advanced computerized pulmonary function testing equipment have made their advent. The measurement of peak expiratory flow rate (PEFR) remains a valuable indicator of pulmonary function. Peak expiratory flow rate is a reliable way of judging the degree of airway obstruction in various

Manuscript received: $4^{\text {th }}$ November 2017

Reviewed: $14^{\text {th }}$ November 2017

Author Corrected: $21^{\text {st }}$ November 2017

Accepted for Publication: $27^{\text {th }}$ November 2017 obstructive lung diseases. The PEFR is an effortdependent parameter, emerging from the large airways within about $100-120 \mathrm{msec}$ of the start of forced expiration. It remains at its peak for $10 \mathrm{msec}$ [1]. It is well documented in literature that a wide range of geographical, climatic, anthropometric, nutritional, and socioeconomic conditions of India are associated with regional differences in lung function[2].

The variety of durable and inexpensive devices for measuring peak flow rates makes it a valuable tool for monitoring airway diseases in the office or home in the management of asthma [3]. The PEFR can be measured by the patient at home [4]. With proper instruction the results can be used to monitor improvement, intercept early worsening and 
measure response to therapy [5]. A peak flow diary can offer the clinician a longitudinal record by which to evaluate disease activity or therapeutic efficacy. A variation of greater than 20 percent of baseline may indicate increases reactivity.

Prediction equations relating peak expiratory flow rate to height, sex and chest circumferences are available for western children, North Indian children and urban South Indian children. As for any parameter used to assess dysfunction, the importance of having regional reference values cannot be overemphasized. The importance of having reference values for Gulbarga is more so because of the large incidence of respiratory disorders here. This study aims to derive predictive normal values of peak expiratory flow rates in children aged 9 to 12 years in Gulbarga.

\section{Materials and Methods}

A total of 510 children with the age of 9 to 12 years of both sexes including 293 boys and 217 girls were selected from class IV to VII of various schools in Gulbarga. Proper consent from the concerned parents and authorities were obtained before the data collection. The children were subjected to a full clinical assessment. Detailed history of cough, expectoration, rhinorrhea and breathlessness were asked. Pediatric reference standard for the lung function were obtained in healthy children who have no present acute or past or present chronic disease of respiratory system, no major respiratory disease such as congenital anomalies, destructive type of pneumonia or thoracic surgery, no more than incidental smoking exposure andno previous URI in preceding three weeks.

Medical information and questionnaire based on the proforma was elicited in local language. Fuel used at home, socioeconomic status (Kuppuswamy's Classification) [6], history of contact with tuberculosis, history of passive smoking, family history of bronchial asthma and family history of chronic illness were recorded in Performa. Height, Weight, and chest circumference was measured using standard procedure. Peak expiratory flow rate measurements were done using standard mini Wright $^{\mathrm{TM}}$ peak flow meter $(60-800 \mathrm{l} / \mathrm{min})$. Each child was asked to take a deep breath and blow into the flowmeter and repeated it for 3-4 times until they were familiar with the procedure. The average of three recording was accepted in each case as the peak expiratory flow rate. Care was taken to clean mouth-piece with suitable disinfectant after each recording. The results were statistically analyzed using ' $\mathrm{t}$ ' test and correlation coefficient.

\section{Results}

Table-1: Mean and SD of Peak Expiratory Flow Rate according to age.

\begin{tabular}{|c|c|c|c|c|}
\hline Age & No. of subject & Mean PEFR & SD & P value \\
\hline 9 & 138 & 217 & 29.44 & $\mathrm{P}<0.001$ \\
\hline 10 & 136 & 240 & 26.30 & $\mathrm{P}<0.001$ \\
\hline 11 & 117 & 279 & 29.17 & $\mathrm{P}<0.05$ \\
\hline 12 & 119 & 274 & 36.72 & $\mathrm{P}<0.001$ \\
\hline
\end{tabular}

It was observed that PEFR increases with age and the increase is statistically significant in all age groups (Table1).

Table-2: Mean and Standard Deviation of Peak Expiratory Flow Rate according to Age and Sex.

\begin{tabular}{|c|c|c|c|c|c|c|c|}
\hline \multirow{2}{*}{$\begin{array}{c}\text { Age in } \\
\text { years }\end{array}$} & \multicolumn{3}{|c|}{ Boys } & \multicolumn{3}{|c|}{ Girls } & \multirow{2}{*}{ P Value } \\
\cline { 2 - 7 } & $\begin{array}{c}\text { No. of } \\
\text { subjects }\end{array}$ & $\begin{array}{c}\text { Mean } \\
\text { PEFR }\end{array}$ & S.D. & $\begin{array}{c}\text { No. of } \\
\text { subjects }\end{array}$ & $\begin{array}{c}\text { Mean } \\
\text { PEFR }\end{array}$ & S.D. & P \\
\hline 9 & 74 & 225 & 23 & 64 & 209 & 33.18 & $\mathrm{P}>05$ \\
\hline 10 & 73 & 240 & 28.62 & 63 & 240 & 23.57 & $\mathrm{P}>0.05$ \\
\hline 11 & 71 & 283 & 29 & 46 & 274 & 27.81 & $\mathrm{P}<0.001$ \\
\hline 12 & 75 & 337 & 36.5 & 44 & 318 & 31.16 & $\mathrm{P}<0.05$ \\
\hline
\end{tabular}

The mean and standard deviation of both sexes of each age was analyzed to find out the difference in PEFR between boys and girls. These results clearly shows boys have PEFR, which is significantly higher in age 11 and 12 years, while in age 9 and 10 years, it is statistically insignificant (Table-2). 
Table-3: Correlation Coefficient Values of Peak Expiratory Flow Rate with Weight, Height, Age and Chest Circumference.

\begin{tabular}{|c|c|c|c|c|}
\hline \multirow{2}{*}{} & \multicolumn{2}{|c|}{ Boys } & \multicolumn{2}{c|}{ Girls } \\
\cline { 2 - 5 } & Correlation coefficient & P Value & Correlation coefficient & P Value \\
\hline Height & 0.82 & $<0.001$ & 0.73 & $<0.001$ \\
\hline Weight & 0.81 & $<0.001$ & 0.69 & $<0.001$ \\
\hline Chest circumference & 0.59 & $<0.001$ & 0.52 & $<0.001$ \\
\hline Age & 0.73 & $<0.001$ & 0.79 & $<0.001$ \\
\hline
\end{tabular}

The values of PEFR obtained for boys and girls were analyzed to find out relationship between peak expiratory flow rate and anthropometric measurement of child. Pearson correlation coefficient was computed for PEFR with height, weight, chest circumference and age. It was deduced that height, weight and chest circumference have a good correlation with peak PEFR in boys (Table-3). As for boys, it was noted that even girls have significant correlation of PEFR with height, weight and chest circumference.

Table-4: Mean and standard deviation of PEFR based on socio-economic status, TB in family, smoking in the family, fuel use for cooking and bronchial asthma in the family.

\begin{tabular}{|c|c|c|c|c|c|}
\hline & & No. of subjects & Mean PEFR & SD & P value \\
\hline \multirow{3}{*}{ Status } & Low & 230 & 261 & 47.85 & \multirow{3}{*}{$\mathrm{P}>0.05$} \\
\hline & Medium & 277 & 265 & 49.03 & \\
\hline & High & 03 & 258 & 68.50 & \\
\hline \multirow{2}{*}{ Tuberculosis } & $\mathrm{H} / \mathrm{O}$ contact with $\mathrm{TB}$ & 25 & 233 & 34.07 & \multirow{2}{*}{$\mathrm{P}<0.001$} \\
\hline & No $\mathrm{H} / \mathrm{O}$ contact $\mathrm{TB}$ & 485 & 265 & 51.98 & \\
\hline \multirow{2}{*}{ Smoking } & $\begin{array}{l}\mathrm{H} / \mathrm{O} \text { contact passive smoking } \\
\text { in family }\end{array}$ & 94 & 250 & 52.90 & \multirow{2}{*}{$\mathrm{P}<0.001$} \\
\hline & $\begin{array}{l}\text { No contact passive smoking in } \\
\text { family }\end{array}$ & 416 & 267 & 50.91 & \\
\hline \multirow{3}{*}{ Fuel used } & Firewood & 243 & 257 & 53.28 & \multirow{3}{*}{$\mathrm{P}<0.001$} \\
\hline & Gas & 262 & 269 & 48.95 & \\
\hline & Kerosene & 05 & 221 & 30.60 & \\
\hline \multirow{2}{*}{ Asthma } & Family history of Asthma & 55 & 242 & 39.43 & \multirow{2}{*}{$\mathrm{P}>0.05$} \\
\hline & No family history of Asthma & 455 & 260 & 52.05 & \\
\hline
\end{tabular}

The peak expiratory flow rate of children was analyzed according to their socioeconomic status. As there were only 5 children in the higher socioeconomic group, the number was statistically insufficient for comparison. Hence, mean peak expiratory flow rate was compared between low and middle socioeconomic groups (Table-4).

Children were analyzed to find out any relation between tuberculosis and peak expiratory flow rate. The results state that children with strong history of contact with tuberculosis in their home have significantly lower values of peak expiratory flow rate (Table-4).

Children analyzed were divided into two groups based on exposure to smoking at home. It was found that, there was a significant decrease in peak expiratory flow rate in children with history of exposure to smoking at home (Table-4). In this study fuel used in cooking at home was found to affect peak expiratory flow rate (Table-4). From the history, children were divided again into two groups based on family history of bronchial asthma. It was seen that family history of bronchial asthma does not influence peak expiratory flow rate (Table- 4). 


\section{Discussion}

The study shows an increase in PEFR with age and it was statistically significant in all age group of study population. Other studies by Donaldson GC et al [7], Janssens $\mathrm{J}$ et al [8] andSteffen TM et al [9] reported a highly significant correlation between age and pulmonary function. The results of PEFR in both sexes of each age shows that, the boys have higher PEFR, which is significantly higher in age 11 and 12 years, while in age 9 and 10 years, it is statistically insignificant. Hence, overall boys had significant higher mean PEFR than girls. The findings were correlating to other studies such as studies by Peterson ML et al[10], Steffen TM et al [9] and Singh AK et al [11].

The relationship between peak expiratory flow rate and anthropometric measurement of child was confirmed with the separate measurement of PEFR in boys and girls. Boys and girls have significant correlation of PEFR with height, weight and chest circumference. In previous studies, Mohammad zadeh I et al [12] observed the best correlation between PEFR and height. Similar observations were made by Eigen $\mathrm{H}$ et al [13], Donaldson GC et al [7] and Pulickal AS et al [14].

Thus, the findings of this study correlate well with other studies that for given age and sex, anthropometric measurement has strong correlation with PEFR. The analysis of peak expiratory flow rate of children according to their socioeconomic status showed no variation in peak expiratory flow rate between both groups. However, Jackson B et al [15] in their study found that, children from low socioeconomic status have lower forced vital capacity.

The results state that the peak expiratory flow rate is significantly lower in children with strong history of contact with tuberculosis in their home. A study by Kosmidis C et al [16] showed that pulmonary tuberculosis can lead to all possible pattern of dysfunction. It has been shown that bronchial compression in tuberculosis can occur by lymph node pressure from outside the bronchus or alternatively perforation of the node may obstruct the bronchus by its contents. In early cases, mild bronchial compression leads to narrow lumen and child can develop wheezing. Thus as obstructive lung disease is possible with tuberculosis; the lower level of peak expiratory flow rate with positive history of contact in the study can be explained and is comparable to the other studies. It was found that, the history of smoking exposure in children at home was significantly decreasing the peak expiratory flow rate. Studies by Palmer $\mathrm{CN}$ et al [17] found that maternal smoking connected with significantly lower peak expiratory flow rate, forced vital capacities and lower peak expiratory flow rate in their children. Li YF et al [18] study showed that father's smoking status during child's lifetime was linearly related to decrease in predicted values of peak expiratory flow rate and maximum mid expiratory flow in total subjects.

The effect was more pronounced in girls. Tsai $\mathrm{CH}$ et al [19] showed that respiratory functions were generally lower in household where fathers smoked. Hence, the finding that passive smoking has a significant effect on peak expiratory flow rate correlates well with the western studies. This study shows a relationship between peak expiratory flow rate and fuel used for cooking at home. Air pollution has been shown to cause or aggravate lung function and hence impair pulmonary function in children. In a study by Chhabra SK et al [20] it was shown nitrogen dioxide was associated with lower forced vital capacity, forced expiratory volume and peak expiratory flow rate. As firewood is associated with high combustion and direct contact with smoke and high level of unburnt gases, the decrease in peak expiratory flow rate may be explained. Urom SE et al [21] observed decreased peak expiratory flow rate in Nigerian men and women chronically exposed to fish drying using burning firewood. But whether peak expiratory flow rate was decreased due to burning firewood or dried fish could not be made out due to technical reasons. Hence, it can be said that this study is comparable to other studies.

Study shows no influence of family history of bronchial asthma with peak expiratory flow rate. In his study Smith AD et al [22] found significant variability in peak expiratory flow rate of Asthmatic children while Pellegrino R et al [23] found peak expiratory flow rate of limited value in assessing degree of severity of Asthma during routine clinical work. The present study showed no significance between exposure to bronchial asthma in family and peak expiratory flow rate because of the fact that all 
children with clinical features of asthma in past and present were excluded from the study.

\section{Conclusion}

Determination of peak expiratory flow rate is an inexpensive and simple method of assessing the severity of airway obstruction in a child with obstructive airway disease. It is of considerable value in monitoring disease, prediction of exacerbation and monitoring therapeutic efficacy. Peak expiratory flow rate increases progressively with age in both sexes. For the given age boys have higher peak expiratory flow rate than girls. Peak expiratory flow rate shows very good correlation with height and weight in both sexes. A History of contact with tuberculosis is associated with lower peak expiratory flow rate. Children coming from homes with firewood being used as a fuel had lower peak expiratory flow-rate. Significant correlation has been found between passive smoking and low peak expiratory flow rate. No significant relation has been found between peak expiratory flow rate and socioeconomic status and family history of bronchial asthma. The peak expiratory flow rate values of children in Gulbarga were comparatively low to those of North Indian and Western children but more compared to urban south Indian children.

Authors contribution- Shiyas KP- Concept, design, data acquisition, analysis, drafting, revising critically and final approval of version to be published.

Gopi Mohan- Contributed to design, data acquisition, analysis of the work. Funding: Nil,

Conflict of interest: None initiated,

Perission from IRB: Yes

\section{List of abbreviations}

PEFR- Peak expiratory flow rate, msecMillisecond, URI-Upper respiratory tract infections

\section{References}

1. Dikshit MB, Raje S, Agrawal MJ.Lung functions with spirometry: an Indian perspective--I. Peak expiratory flow rates.Indian J Physiol Pharmacol. 2005 Jan; 49(1):8-18.

2. Raju PS, Prasad KV, Ramana YV, Murthy KJ. Pulmonary function tests in Indian girls--prediction equations. Indian J Pediatr. 2004Oct;71(10):893-7.
3. Spruit MA, Singh SJ, Garvey C, et al ATS/ERS Task Force on Pulmonary Rehabilitation. An official American Thoracic Society /European Respiratory Society statement: key concepts and advances in pulmonary rehabilitation. Am J RespirCrit Care Med. 2013 Oct15;188(8):e13-64. doi: 10.1164/rccm. 201309-1634ST.

4. Gøtzsche PC, Johansen HK. House dust mite control measures for asthma: systematic review. Allergy. 2008 Jun; 63 (6): 646-59. doi: 10.1111/j. 1398-9995. 2008.01690.x.

5. van der Kooi E, Klarenbeek NB, Güler-Yüksel M, Kerstens PJ, van der Lubbe PA, Westedt ML, ten Wolde S, Huizinga TW, Dijkmans BA, Allaart CF. A decrease in disease activity score (DAS) level is associated with a decrease in health assessment questionnaire (HAQ) score, independent of followup duration, during 5 years of tightly controlled treatment: results from the BeSt study. Ann Rheum Dis. 2011 Jan;70(1):168-71. doi: 10.1136/ard. 2010. 133132. Epub 2010 Nov 29.

6. Sharma R. Kuppuswamy's socioeconomic status scale--revision for 2011 and formula for real-time updating. Indian J Pediatr. 2012 Jul; 79(7): 961-2. doi: 10. 1007 /s12098-011- 0679-3. Epub 2012 Jan 10 .

7. Donaldson GC, Seemungal TA, Bhowmik A, Wedzicha JA.Relationship between exacerbation frequency and lung function decline in chronic obstructive pulmonary disease.Thorax. 2002 Oct; 57 (10): 847-52.

8. Janssens JP, Pache JC, Nicod LP. Physiological changes in respiratory function associated with ageing. Eur Respir J. 1999 Jan; 13 (1): 197205.

9. Steffen TM, Hacker TA, Mollinger L. Age- and gender-related test performance in communitydwelling elderly people: Six-Minute Walk Test, Berg Balance Scale, Timed Up \& Go Test, and gait speeds. Phys Ther. 2002 Feb;82(2):128-37.

10. Peterson ML, Jacobs DR Jr, Milla CE. Longitudinal changes in growth parameters are correlated with changes in pulmonary function in children with cystic fibrosis. Pediatrics. 2003 Sep; 112 (3 Pt 1): 588-92. 
11. Singh AK, Cydulka RK, Stahmer SA, Woodruff PG, Camargo CA. Sex differences among adults presenting to the emergency department with acute asthma. Archives of internal medicine. 1999 Jun 14; 159 (11):1237-43.

12. Mohammadzadeh I, Gharagozlou M, Fatemi SA. Normal values of peak expiratory flow rate in children from the town of Babol, Iran.Iran J Allergy Asthma Immunol. 2006 Dec;5(4):195-8.

13. Eigen H, Bieler H, Grant D, Christoph K, Terrill D, Heilman DK, Ambrosius WT, Tepper RS. Spirometric pulmonary function in healthy pre school children. Am J Respir Crit Care Med. 2001 Mar; 163 (3 Pt 1):619-23.

14. Pulickal AS, Fernandez GV. Peak expiratory flow rate in healthy rural south Indian school children predicted from body height. Editorial Board Vol. 51 No. 2 April-June 2007. 2007 Apr 5;51(2).

15. Jackson B, Kubzansky LD, Cohen S, Weiss S, Wright RJ. A matter of life and breath: childhood socioeconomic status is related to young adult pulmonary function in the CARDIA study. International journal of epidemiology. 2004 Apr 1; 33 (2):271-8.

16. Kosmidis C, Denning DW. The clinical spectrum of pulmonary aspergillosis. Thorax. 2015 Mar; 70 (3): 270-7. doi: 10.1136/ thoraxjnl-2014206291. Epub 2014 Oct 29.

17. Palmer CN, Doney AS, Lee SP, Murrie I, Ismail T, Macgregor DF, Mukhopadhyay S. Glutathione Stransferase M1 and P1 genotype, passive smoking, and peak expiratory flow in asthma.Pediatrics. 2006 Aug; 118(2):710-6.
18. Li YF, Gilliland FD, Berhane K, Mcconnell RO, James Gauderman W, Rappaport EB, Peters JM. Effects of in utero and environmental tobacco smoke exposure on lung function in boys and girls with and without asthma. American journal of respiratory and critical care medicine. 2000 Dec 1; 162 (6):2097-104.

19. Tsai CH, Huang JH, Hwang BF, Lee YL. Household environmental tobacco smoke and risks of asthma, wheeze and bronchitic symptoms among children in Taiwan. Respiratory research. 2010 Dec 1; 11 (1):11.

20. Chhabra SK, Chhabra P, Rajpal S, Gupta RK.Ambient air pollution and chronic respiratory morbidity in Delhi. Arch Environ Health. 2001JanFeb; 56(1):58-64.

21. Urom SE, Antai AB, Osim EE. Symptoms and lung function values in Nigerian men and women exposed to dust generated from crushing of granite rocks in Calabar, Nigeria. Nigerian Journal of Physiological Sciences. 2004;19(1):41-7.

22. Smith AD, Cowan JO, Filsell S, Mc Lachlan C, Monti-Sheehan G, Jackson P, Taylor DR. Diagnosing asthma: comparisons between exhaled nitric oxide measurements and conventional tests. Am J RespirCrit Care Med.2004Feb15;169(4):4738. Epub 2003 Nov 25.

23. Pellegrino R, Viegi G, Brusasco V, Crapo RO, Burgos F, Casaburi R, Coates A, van der Grinten CP, Gustafsson P, Hankinson J, Jensen R, Johnson DC, MacIntyre N, McKay R, Miller MR, Navajas $\mathrm{D}$, Pedersen OF, Wanger J. Interpretative strategies for lung function tests.EurRespir J.2005Nov; 26 (5): 948-68.

\section{How to cite this article?}

Shiyas K.P, Gopi Mohan. Factors Affecting Peak Expiratory Flow Rates in Children of 9-12 Years of Age. Int J Pediatr Res. 2017;4(11):651-656.doi:10. 17511/ijpr.2017.i11.04. 